\title{
Quantification of the kokumi peptide, y-glutamyl-valyl-glycine, in cheese: Comparison between cheese made from cow and ewe milk
}

\author{
Motonaka Kuroda, ${ }^{1 *}$ ๑ Keita Sasaki, $^{1}$ Junko Yamazaki, ${ }^{2}$ Yumiko Kato, ${ }^{2}$ and Toshimi Mizukoshi ${ }^{2}$ \\ ${ }^{1}$ Institute of Food Research and Technologies, Ajinomoto Co. Inc., 1-1 Suzuki-cho, Kawasaki-ku, Kawasaki, Kanagawa 210-8681, Japan \\ ${ }^{2}$ Institute for Amino Sciences, Ajinomoto Co. Inc., 1-1 Suzuki-cho, Kawasaki-ku, Kawasaki, Kanagawa 210-8681, Japan
}

\begin{abstract}
Recent studies have shown that several types of cheese contain kokumi $\gamma$-glutamyl dipeptides, and the kokumi tripeptide, $\gamma$-glutamyl-valyl-glycine ( $\gamma$-GluVal-Gly), is a component of various fermented foods. The quantification of $\gamma$-Glu-Val-Gly in various types of cheese was herein conducted by HPLC-tandem mass spectrometry followed by derivatization with 6 -aminoquinoyl- $N$-hydroxysuccinimidyl-carbamate. The $\gamma$-Glu-Val-Gly concentrations were between 0.35 and $0.59 \mu \mathrm{g} / \mathrm{g}$ in cheese made from ewe milk, but were not detected in cheese made from cow milk. The amino acid sequences of major milk proteins showed that the $\beta$-caseins of sheep had the Val-Gly sequence at the 9-10 position, whereas $\beta$-caseins of cows contained a Pro-Gly sequence at the same position. The Val-Gly sequence was absent in other caseins of sheep and cattle. These results suggest that the different $\gamma$-Glu-Val-Gly concentrations present in cheese made from cow and ewe milk are due to differences in the amino acid sequences of caseins.
\end{abstract}

Key words: cheese, cow milk, ewe milk, $\gamma$-glutamylvalyl-glycine, kokumi

\section{INTRODUCTION}

Cheese is consumed worldwide due to its characteristic flavor and nutritional value. Previous studies clarified the balance of compounds that contribute to the 5 basic tastes (sweet, salty, sour, bitter, and umami) of cheese (Biede and Hammond, 1979; Aston and Creamer, 1986; Fox et al., 2004), and suggested that reconstitution by low-molecular-weight compounds, such as amino acids, organic acids, minerals, and sugars can reproduce the basic taste balance of cheese. However, the complex cheese taste could not be reconstituted

Received March 12, 2020.

Accepted May 1, 2020.

*Corresponding author: motonaka_kuroda@ajinomoto.com by mixing the above low-molecular-weight compounds (Toelstede et al., 2009).

The taste attributes of cheese and various foods cannot be solely explained by the 5 basic tastes. Ueda et al. (1990) previously attempted to isolate and identify the key compounds responsible for the flavoring effects of a water extract of garlic that increased continuity, mouthfulness, and thickness when added to an umami solution, and that sulfur-containing compounds such as S-allylcysteine sulfoxide (alliin) and glutathione ( $\gamma$-glutamylcysteinyl-glycine; GSH) contributed to these effects. Although these compounds have only a slight flavor in water, they were found to markedly increase thickness, continuity, and mouthfulness when added to an umami solution or other food (Ueda et al., 1997). This group suggested using the term "kokumi substances" for these properties. The effects of kokumi substances, such as GSH, were subsequently shown to be perceived through the calcium-sensing receptor (CaSR) in humans (Ohsu et al., 2010; Maruyama et al., 2012). The findings obtained in these studies confirmed the activation of human CaSR by GSH in addition to several $\gamma$-glutamyl-peptides, including $\gamma$-Glu-Ala, $\gamma$-Glu-Val, $\gamma$-Glu-Cys, $\quad \gamma$-Glu- $\alpha$-aminobutyryl-Gly (ophthalmic acid), and $\gamma$-glutamyl-valyl-glycine ( $\gamma$-Glu-Val-Gly). These compounds were exhibited the characteristics of kokumi substances, and a positive correlation between the CaSR activities of these $\gamma$-glutamyl peptides and the sensory activity of kokumi substances. These results suggest that kokumi substances are perceived through the CaSR in humans. Among these, $\gamma$-Glu-Val-Gly has been reported to be a potent kokumi peptide, and the sensory activity of kokumi substances assessed using the Point of Subjective Equivalent (PSE) method in salty-umami solution was found to be 12.8 -fold stronger than that of GSH (Ohsu et al., 2010).

Previous studies using the sensometric approach demonstrated that several kokumi peptides have been detected in several types of cheese (Toelstede et al., 2009; Toelstede and Hofmann, 2009; Hillmann et al., 2016) and contribute to flavor by increasing complexity, continuity, and mouthfulness. Toelstede et al. (2009) 
identified the following as kokumi peptides in mature Gouda cheese: $\gamma$-glutamyl-glutamic acid $(\gamma$-Glu-Glu), $\gamma$-glutamyl-glycine $(\gamma$-Glu-Gly), $\gamma$-glutamyl-glutamine $(\gamma$-Glu-Gln), $\quad \gamma$-glutamyl-methionine $\quad(\gamma$-Glu-Met $)$, $\gamma$-glutamyl-leucine $\quad(\gamma$-Glu-Leu $), \quad \gamma$-glutamyl-valine $(\gamma$-Glu-Val), and $\gamma$-glutamyl-histidine ( $\gamma$-Glu-His). Toelstede and Hofmann (2009) detected these kokumi peptides in other types of cheese, such as goat cheese, Miner, Camembert, Mouton, Kemhan, Leerdammer, Swiss Gruyere, and Blue Shropshire, and the same peptides were also present in Parmesan cheese (Hillmann et al., 2016). Regarding the biogeneration of kokumi peptides, Toelstede and Hofmann (2009) showed that these kokumi $\gamma$-glutamyl dipeptides were formed by the action of $\gamma$-glutamyl transferase from Penicillium roquefortii during the maturation process of cheese. Furthermore, Hillmann et al. (2016) reported that $\gamma$-glutamyl transferase in raw milk was responsible for the biogeneration of kokumi $\gamma$-glutamyl peptides during the maturation of Parmesan cheese. These findings demonstrated that several kokumi $\gamma$-glutamyl dipeptides contribute to the flavor of mature cheese and also that these peptides are formed by $\gamma$-glutamyl transferase during the maturation process of cheese.

$\gamma$-Glutamyl-valyl-glycine ( $\gamma$-Glu-Val-Gly), which is a potent kokumi $\gamma$-glutamyl peptide, has been detected in fermented foods, such as fish sauce (Kuroda et al., 2012b; Miyamura et al., 2015), soy sauce (Kuroda et al., 2013), fermented shrimp paste (Miyamura et al., 2014), and beer (Miyamura et al., 2015). A recent study reported the presence of $\gamma$-Glu-Val-Gly in some fermented Thai freshwater fish ( $p l a r a$ ) (Phewpan et al., 2019). Because this peptide has not been detected in the raw materials of these fermented foods, it may be formed during the fermentation process. The biosynthesis of $\gamma$-Glu-Val-Gly appears to involve the dipeptide L-valylglycine (Val-Gly) because the fermented foods listed above are produced by proteolysis. Furthermore, the $\gamma$-glutamylization of Val-Gly has been implicated in the formation of $\gamma$-Glu-Val-Gly (Kuroda et al., 2013). These findings suggest that $\gamma$-Glu-Val-Gly is present in fermented dairy foods; however, its presence in cheese has not yet been confirmed. The quantification of $\gamma$-Glu-Val-Gly concentrations in commercial cheese from cow and ewe milk was conducted and the contents were compared.

\section{MATERIALS AND METHODS}

\section{Chemicals}

$\gamma$-Glutamyl-Val-Gly was purchased from Ajinomoto Co. Inc. (Tokyo, Japan), the stable isotope L-Ala- $d_{3}$ from Isotec (Tokyo, Japan), and the AccQ Fluor reagent kit from Waters (Milford, MA). The mobile phase (MP) consisted of HPLC-grade acetonitrile (Junsei Chemicals Co. Ltd., Osaka, Japan) and formic acid (99\%, Wako Pure Chemical Industries Ltd., Osaka, Japan), and the Milli-Q system (Millipore, Billerica, MA) was used to provide deionized water.

\section{Cheese Brands}

Five brands of cheese made from cow milk and 3 brands of cheese from ewe milk were purchased from Japanese markets and used in the present study. We also selected various cheese types including hard, semihard type, molded, and washed-rind cheese. The following cheese samples from cow milk were examined: Cheddar A (semi-hard type, 4 mo ripened), Cheddar B (semi-hard type, 12 mo ripened), Saint Agur (blue cheese), Stilton (blue cheese), and Langres (washed-rind cheese). Cheese samples from ewe milk were as follows: Pecorino Romano (hard type), Manchego (semi-hard type), and Ossau Iraty (semi-hard type). A list of the raw materials and types of cheese used is summarized in Table 1. These samples were stored at $4^{\circ} \mathrm{C}$ for later analyses.

\section{Preparation of Samples and Protocol for Derivatization}

Cheese samples were added to deionized water, homogenized, and the resulting suspension was filtered

Table 1. The characteristics and contents of general components in various commercial cheeses

\begin{tabular}{llll}
\hline Samples & Country of origin & Raw materials & Type of cheese \\
\hline Cheddar A & United Kingdom & Cow milk, salt & Semi-hard type \\
Cheddar B & United Kingdom & Cow milk, salt & Semi-hard type \\
Saint Agur & France & Cow milk, salt & Blue cheese \\
Stilton & United Kingdom & Cow milk, salt & Blue cheese \\
Langres & France & Cow milk, salt & Wash cheese \\
Pecorino Romano & Italy & Ewe milk, salt & Hard type \\
Manchego & Spain & Ewe milk, salt & Semi-hard type \\
Ossau Iraty & France & Ewe milk, salt & Semi-hard type \\
\hline
\end{tabular}


using a $0.45-\mu \mathrm{m}$ syringe filter $(25 \mathrm{~mm} \mathrm{GD} / \mathrm{X}$ Disposable Filter Device, Whatman Corp.) to remove insoluble matter. Filtrates were then filtered through the $10 \mathrm{~K}$ Amicon Ultra Centrifugal Filter Device (regenerated cellulose 10,000 molecular-weight cut-off, Millipore) at $7,500 \times g$ at $4^{\circ} \mathrm{C}$ for $15 \mathrm{~min}$. Samples were then stored at $-20^{\circ} \mathrm{C}$ before being derivatized. The $\gamma$-Glu-Val-Gly, which naturally occurs in cheese, was derivatized with the 6-aminoquinoyl- $N$-hydroxysuccinimidyl-carbamate (AQC) reagent (AccQ Fluor reagent kit, Millipore) coupled with liquid chromatography/tandem mass spectroscopy (LC/MS/MS). The AQC powder was dissolved in acetonitrile as described in the supplier's instructions (https://www.waters.com/webassets/ cms/support/docs/715001331.pdf). The procedure for derivatization was as follows. Five microliters of the cheese sample solution described above was added to $60 \mu \mathrm{L}$ of borate buffer, $10 \mu \mathrm{L}$ of an internal standard solution containing $5 \mu \mathrm{M}$ L-Ala- $d_{3}, 20 \mu \mathrm{L}$ of the AQC reagent solution, and $5 \mu \mathrm{L}$ of deionized water (for unspiked samples) or $5 \mu \mathrm{L}$ of the standard $\gamma$-Glu-Val-Gly solution at 4 different concentrations to quantify the standard addition method. Samples were then heated at $55^{\circ} \mathrm{C}$ for $10 \mathrm{~min}$, followed by the addition of $200 \mu \mathrm{L}$ of $0.1 \%$ aqueous formic acid, and then analyzed by LC/ MS/MS.

\section{LC and MS Conditions}

Following its derivatization, $\gamma$-Glu-Val-Gly was examined by LC/MS/MS. Separation was performed using the AQUITY Ultra Performance LC system (Waters Corp.) and detection by the AB SCIEX QTrap 5500 system (AB SCIEX). Derivatized $\gamma$-Glu-Val-Gly was separated by reversed-phase HPLC using the Imtakt Unison UK-Phenyl column $(2.0 \mathrm{~mm}$ i.d. $\times 100 \mathrm{~mm}, 3$ $\mu \mathrm{m})$ at a column temperature of $40^{\circ} \mathrm{C}$. Mobile phase A contained $25 \mathrm{~m} M$ aqueous ammonium formate ( $\mathrm{pH}$ 6.0, adjusted by an aqueous ammonium solution), whereas MP B was methanol. Elution conditions were as follows: 0 min (5\% MP B), $10 \min (20 \% \mathrm{MP}$ B), 10.1 to $12 \min (80 \% \mathrm{MP} \mathrm{B})$, and 12.1 to $18 \min (5 \% \mathrm{MP} \mathrm{B})$ at a flow rate of $0.25 \mathrm{~mL} / \mathrm{min}$, which was maintained for the entire analysis. Ten microliters of derivatized samples was used in the analysis. The multiple reaction monitoring (MRM) mode was employed to measure AQC-derivatized $\gamma$-Glu-Val-Gly. Data from the MRM mode to detect $\gamma$-Glu-Val-Gly and L-Ala- $d_{3}$ were simultaneously collected in a single run. The IS (IonSpray Voltage), TEM, CUR, and GS1 and GS2 parameters were $5,500 \mathrm{~V}, 600^{\circ} \mathrm{C}, 30 \mathrm{psi}$, and 50 and $80 \mathrm{psi}$, respectively. The parameters of the MRM mode to detect AQC-derivatized $\gamma$-Glu-Val-Gly were as follows: the precursor ion mass (Q1), fragment ion mass (Q3), and collision energy (CE) were 472.2 Da, 171.2 Da, and 50 $\mathrm{V}$, respectively. The parameters of the MRM mode to detect AQC-derivatized L-Ala- $d_{3}$ were as follows: Q1, Q3, and CE were set to 263.0 Da, 171.1 Da, and 30 V, respectively. The AQC-derivatized $\gamma$-Glu-Val-Gly was identified by MS/MS/MS. The first Q1, second precursor ion mass (Q3), scan rate, CE, and excitation energy (AF2) were 474.2 Da, 304.3 Da, 10,000 Da/s, $21 \mathrm{~V}$, and $45 \mathrm{mV}$, respectively, whereas the second product ion mass was between 50 and 400 Da.

\section{RESULTS AND DISCUSSION}

\section{Detection of y-Glu-Val-Gly in Cheese Samples}

The AQC-derivatized $\gamma$-Glu-Val-Gly was identified in the samples by a MS/MS/MS fragmentation pattern analysis. Mass chromatograms obtained from standard $\gamma$-Glu-Val-Gly and a cheese sample (Manchego) are shown in Figure 1A and 1B, respectively. The MRM transition channel of $474.2 / 304.3$, which is the most sensitive, was used to monitor mass chromatograms. A peak at 8.33 min (retention time) was detected in the standard sample (Figure 1A) and appeared to correspond to that of AQC-derivatized $\gamma$-Glu-Val-Gly. It was also detected in a cheese sample (Figure 1B), due to its complex chromatogram pattern; however, difficulties were associated with confirming whether $\gamma$-Glu-Val-Gly was present based only on the retention time and single MRM data. Figure 2 shows the MS/MS/MS fragment ions of the derivatized standard $\gamma$-Glu-Val-Gly (A) and a cheese sample (Manchego; B). The ion detected at 304.1 was a second precursor ion and assigned as the $\gamma$-Glu-Val-Gly moiety. Furthermore, the fragment ions at 175.1 and 229.2, which are characteristic of the $\gamma$-Glu-Val-Gly molecule, were identical. As shown in Figure 3, the fragment ion at 229.2 was assigned as the $\gamma$-Glu-Val moiety bearing a carbocation at its $\mathrm{C}$ terminus, whereas the fragment ion at 175.1 was the Val-Gly moiety. These spectrum data are consistent and suggest that $\gamma$-Glu-Val-Gly concentrations in cheese samples are quantifiable by LC/MS/MS. Figures 3 and 4 .

\section{Y-Glu-Val-Gly Concentrations in Cheese Samples}

$\gamma$-Glu-Val-Gly concentrations in the cheese types examined are shown in Table 2. Although $\gamma$-Glu-Val-Gly was not detected in cheeses made from cow milk, it was present in those made from ewe milk at concentrations ranging between 0.37 and $0.59 \mu \mathrm{g} / \mathrm{g}$. Among the types of cheese made from ewe milk, Manchego contained the highest concentration of $\gamma$-Glu-Val-Gly $(0.59 \mu \mathrm{g} / \mathrm{g})$, whereas Ossau Iraty contained the lowest amount $(0.35 \mu \mathrm{g} / \mathrm{g})$. Although the 3 types of cheese 

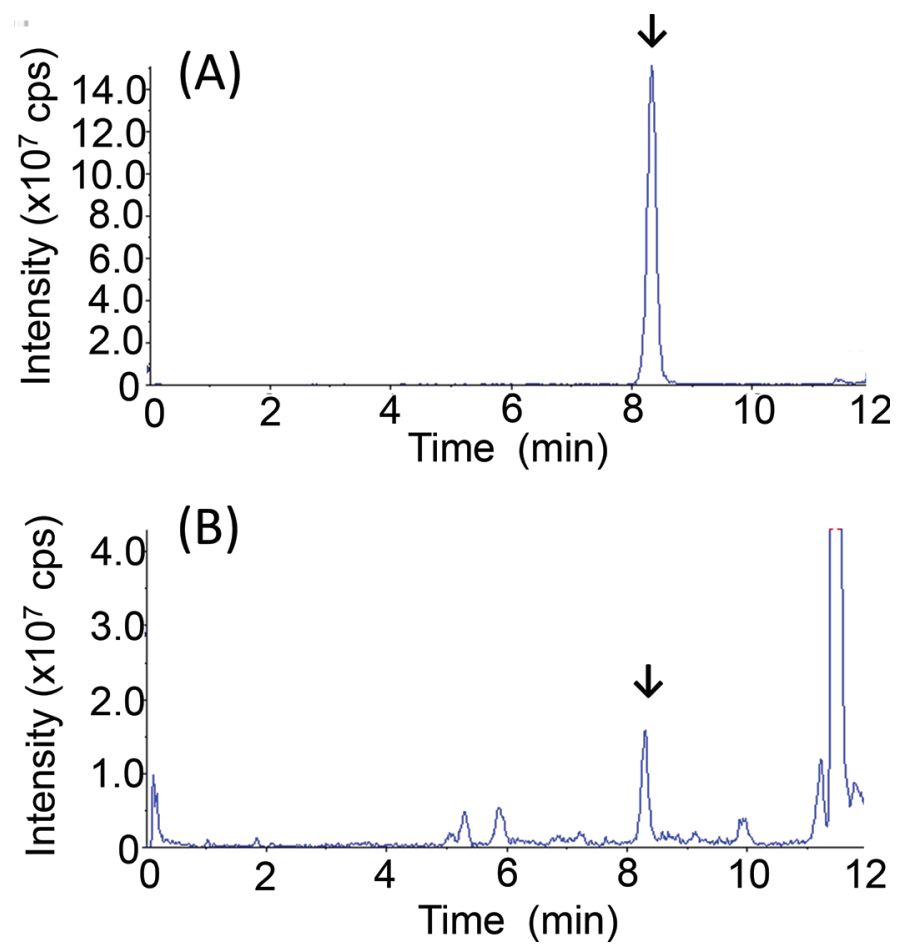

Figure 1. Liquid chromatography/tandem mass spectroscopy (LC/MS/MS) chromatogram obtained from the 6-aminoquinoyl$N$-hydroxysuccinimidyl-carbamate (AQC)-derivative of standard $\gamma$-glutamyl-valyl-glycine ( $\gamma$-Glu-Val-Gly; A) and an AQC-derivatized cheese (Manchego) sample (B). The pair of precursor and fragment ions at the multiple reaction monitoring transition channel was 474.2/304.2. Arrows indicate peaks that correspond to $\gamma$-Glu-Val-Gly.

from ewe milk varied in their origin countries and types (Pecorino Romano is a hard type, whereas Manchego and Ossau Iraty are semi-hard types), $\gamma$-Glu-Val-Gly was present in all cheese samples from ewe milk. In this study, $\gamma$-Glu-Val-Gly was not detected in cheese from cow milk. It has been reported that cheese from cow milk such as Gouda and Parmesan contains several kinds of kokumi $\gamma$-glutamyl-dipeptides such as $\gamma$-GluGlu, $\gamma$-Glu-Gly, $\gamma$-Glu-Gln, $\gamma$-Glu-Met, $\gamma$-Glu-Leu, $\gamma$-Glu-Val, and $\gamma$-Glu-His. Therefore, these kokumi $\gamma$-glutamyl-dipeptides function as kokumi substances in cheese from cow milk. Furthermore, the previous study revealed that cheese from ewe milk, Mouton, also contained these kokumi $\gamma$-glutamyl-dipeptides (Toelstede and Hofmann, 2009), indicating that $\gamma$-Glu-Val-Gly and these kokumi $\gamma$-glutamyl-dipeptides contribute as kokumi substances in cheese from ewe milk.

\section{Assessment of the Potent Precursor Peptide in Proteins in Ewe Milk}

We previously identified $\gamma$-Glu-Val-Gly in various fermented foods, such as traditional fish sauces $(\mathrm{Ku}-$ roda et al., 2012b), fish sauces made using koji (Miyamura et al., 2016), soy sauces (Kuroda et al., 2013), fermented shrimp pastes (Miyamura et al., 2014), and beer (Miyamura et al., 2015). Since $\gamma$-Glu-Val-Gly was not detected in the raw materials of these foods, such as fish (unpublished data), $\gamma$-Glu-Val-Gly may have been formed in one of the stages of the fermentation process. Val-Gly is also a substrate of $\gamma$-glutamyltransferase (GGT; Suzuki and Yamada, 2007). The proteolytic action that occurs during the fermentation process of cheese promotes the release of Val-Gly. Therefore, the biosynthesis of $\gamma$-Glu-Val-Gly may involve GGT and Val-Gly, which was formed by the proteolysis of milk proteins, mainly caseins. Among the various cheese samples tested, Toelstede and Hofmann (2009) identified kokumi $\gamma$-glutamyl peptides as the most abundant in Blue Shropshire. Furthermore, they reported that these peptides were biosynthesized by the action of GGT from Penicillium roquefortii, which was detected in Blue Shropshire. Therefore, the formation of kokumi $\gamma$-glutamyl peptides during cheese production may involve GGT from fungi. Zhao and Ganzle (2016) recently demonstrated the synthesis of several kokumi $\gamma$-glutamyl peptides during the fermentation of sourdough by GGT from Lactobacillus reuteri. These bacteria were also found in cheese (BautistaGallego et al., 2014), which suggests that GGT from lactic acid bacteria is also involved in the formation of kokumi $\gamma$-glutamyl peptides. Hillmann et al. (2016) also demonstrated that $\gamma$-glutamyl transferase in raw milk promoted the biogeneration of kokumi $\gamma$-glutamyl peptides during the maturation of Parmesan cheese. Furthermore, GGT activity was detected in ewe milk (Maden et al., 2003; Johnston et al., 2004). These findings indicate that the biosynthesis of $\gamma$-Glu-Val-Gly involves the $\gamma$-glutamylation of Val-Gly by GGT in milk or microbes, such as fungi and lactic acid bacteria, during the fermentation process of cheese.

The present results revealed $\gamma$-Glu-Val-Gly in cheese made from ewe milk, but not in that made from cow milk. To clarify this discrepancy, we developed a casein protein database using data from the National Center for Biotechnology Information Protein database and elucidated the amino acid sequences of caseins in cow milk (Stewart et al., 1984; Jimenez-Flores et al., 1987; Schlieben et al., 1991) and those in ewe milk (Mercier et al., 1985; Boisnard et al., 1991; Provot et al., 1995). As shown in Figure 4, the amino acid sequences of caseins indicated that the $\beta$-casein of sheep had the Val-Gly sequence at the 9-10 position (Provot et al., 1995; Ah-Leung et al., 2006), whereas that of cattle had the Pro-Gly sequence at the same position (JimenezFlores et al., 1987; Stewart et al., 1984; Bonsing et al., 1988). The Val-Gly sequence was absent in the other 


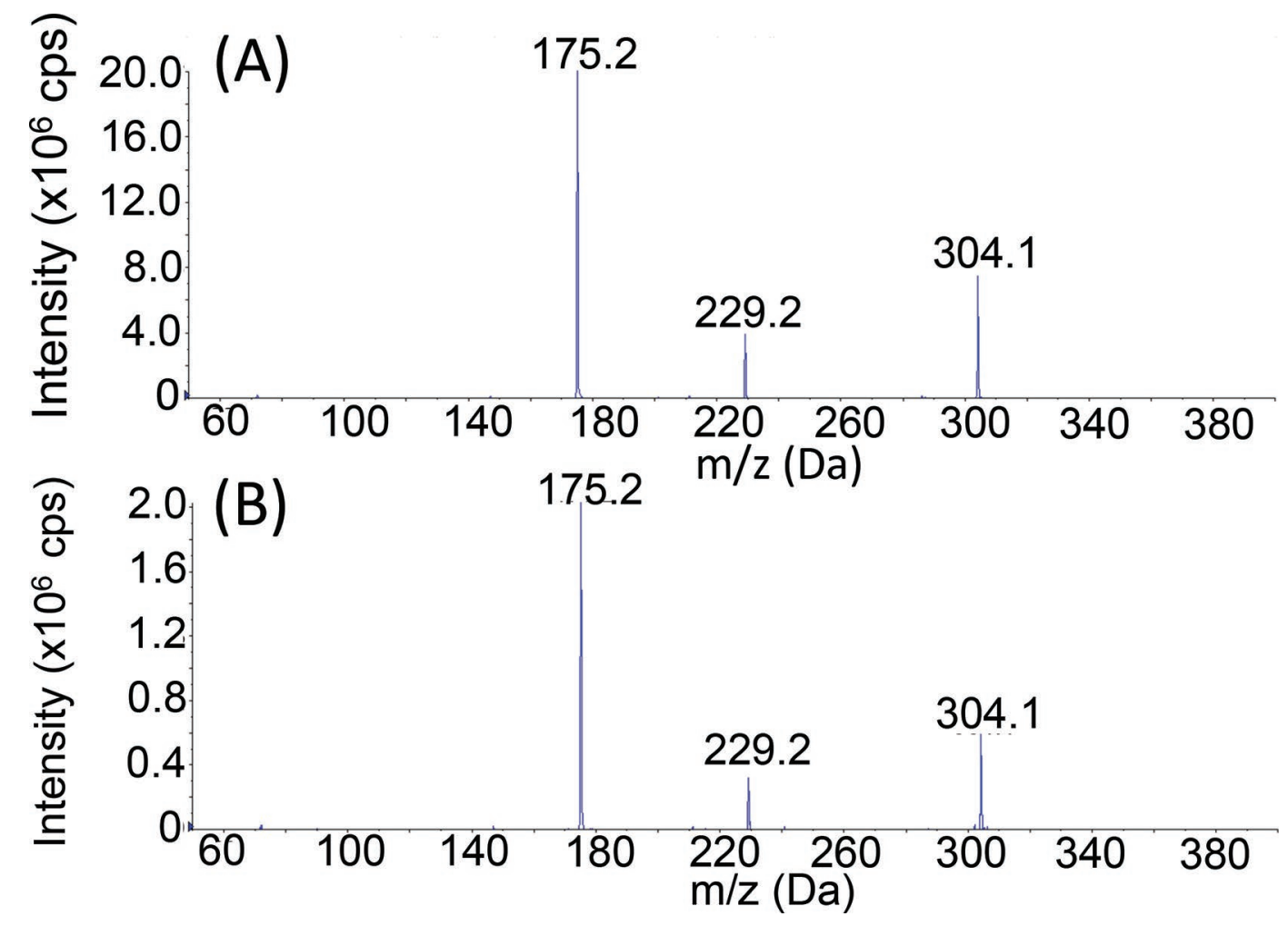

Figure 2. MS/MS/MS fragment ions. (A) Mass spectrum obtained from the 6-aminoquinoyl- $N$-hydroxysuccinimidyl-carbamate (AQC)derivative of standard $\gamma$-glutamyl-valyl-glycine ( $\gamma$-Glu-Val-Gly). (B) Mass spectrum obtained from the AQC-derivatized cheese (Manchego) sample.

caseins $\left(\alpha_{\mathrm{S} 1^{-}}\right.$-asein, $\alpha_{\mathrm{S} 2^{-}}$casein, and $\kappa$-casein) of sheep and cattle. Therefore, $\gamma$-Glu-Val-Gly concentrations appear to differ between cheese made from cow and ewe milk due to differences in the amino acid sequences of the milk protein.

The sensory profiles of cheese made from cow and ewe milk using the same cheese-making method were previously compared using a descriptive analysis (Ferreira et al., 2006). The findings obtained showed that the flavor

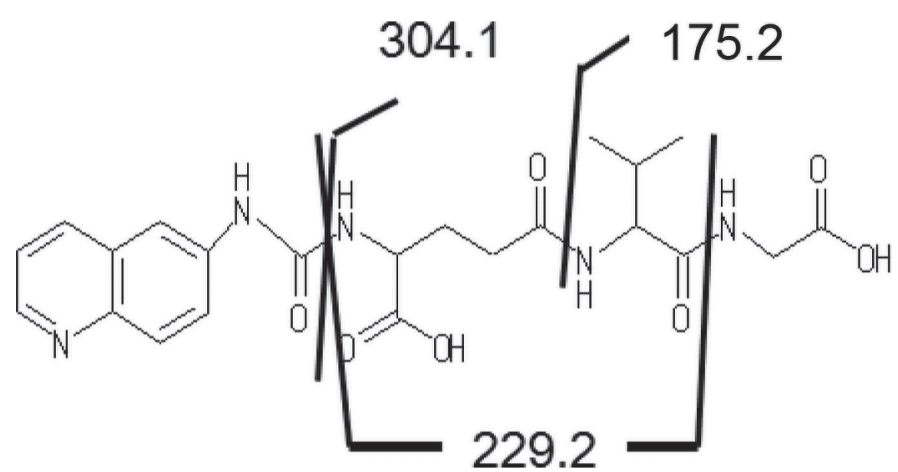
MS. intensity of cheese made from ewe milk was higher than cheese made from cow milk. Regarding the effects of $\gamma$-Glu-Val-Gly on the sensory profiles of dairy foods, we previously demonstrated that the addition of $\gamma$-GluVal-Gly to reduced-fat cream increased thickness as well as the continuity of taste (Kuroda and Miyamura, 2015; Kuroda and Miyamura, 2019). Although it currently remains unclear whether $\gamma$-Glu-Val-Gly affects the sensory characteristics of cheese, this peptide may contribute to the flavor of cheese made from ewe milk. However, further studies are needed to clarify this.

In conclusion, the present study identified and quantified the kokumi peptide, $\gamma$-Glu-Val-Gly, in cheese made

\section{Cattle $6 \quad 10 \quad 15$ (Bovine) Leu-Asn-Val-Pro-Gly-Glu-Ile-Val-Glu-Ser- Sheep $6 \quad 10$ (Ovine) Leu-Asn-Val-Val-Gly-Glu-Thr-Val-Glu-Ser-}

Figure 4. Partial AA sequences of $\beta-\mathrm{CN}$ from cattle (Bos taurus) and sheep (Ovis aries). 
Table 2. The contents of $\gamma$-glutamyl-valyl-glycine ( $\gamma$-Glu-Val-Gly) in various commercial cheeses

\begin{tabular}{|c|c|c|}
\hline Samples & $\begin{array}{l}\text { Origin } \\
\text { of milk }\end{array}$ & $\begin{array}{l}\text { Contents of } \gamma \text {-Glu-Val-Gly }{ }^{1} \\
(\mu \mathrm{g} / \mathrm{g})\end{array}$ \\
\hline Cheddar A & Cow & Not detected \\
\hline Cheddar B & Cow & Not detected \\
\hline Saint Agur & Cow & Not detected \\
\hline Stilton & Cow & Not detected \\
\hline Langres & Cow & Not detected \\
\hline Pecorino Romano & Ewe & 0.40 \\
\hline Manchego & Ewe & 0.59 \\
\hline Ossau Iraty & Ewe & 0.35 \\
\hline
\end{tabular}

${ }^{1}$ Mean value $(\mathrm{n}=3)$. Limit of detection $=0.03 \mu \mathrm{g} / \mathrm{g}$.

from ewe milk and is the first to confirm its presence in cheese.

\section{ACKNOWLEDGMENTS}

We thank Kiyoshi Miwa and Naohiro Miyamura of Ajinomoto Co. Inc. (Tokyo, Japan) for their encouragement and support of this work. We also express our gratitude to Kumiko Ninomiya and Yuko Iida, of Ajinomoto Co. Inc., for their discussions and assistance. The authors have not stated any conflicts of interest.

\section{REFERENCES}

Ah-Leung, S., H. Bernard, E. Bidat, E. Paty, F. Rance, P. Scheinmann, and J. M. Wal. 2006. Allergy to goat and sheep milk without allergy to cow's milk. Allergy 61:1358-1365. https://doi.org/ 10.1111/j.1398-9995.2006.01193.x.

Aston, J. W., and L. K. Creamer. 1986. Contribution of the components of water-soluble fraction to the flavor of Cheddar cheese. N. Z. J. Dairy Sci. Technol. 21:229-248.

Bautista-Gallego, J., V. Alessandria, M. Fontana, S. Bisotti, S. Taricco, P. Dolci, L. Cocolin, and K. Rantsiou. 2014. Diversity and functional characterization of Lactobacillus ssp. isolated throughout the ripening of a hard cheese. Int. J. Food Microbiol. 181:6066. https://doi.org/10.1016/j.ijfoodmicro.2014.04.020.

Biede, S. L., and E. G. Hammond. 1979. Swiss cheese flavor II. Organoleptic analysis. J. Dairy Sci. 62:238-248. https://doi.org/10 .3168/jds.S0022-0302(79)83231-2.

Boisnard, M., D. Hue, C. Bouniol, J. C. Mercier, and P. Gaye. 1991. Multiple mRNA species code for two non-allelic forms of ovine alpha S2-casein. Eur. J. Biochem. 201:633-641. https://doi.org/10 $.1111 / \mathrm{j} .1432-1033.1991 . t b 16324 . x$

Bonsing, J., J. M. Ring, A. F. Stewart, and A. G. Mackinlay. 1988. Complete nucleotide sequence of the bovine beta-casein gene. Aust. J. Biol. Sci. 41:527-537. https://doi.org/10.1071/BI9880527.

Ferreira, I. M. P. L. V. O., C. Veiros, O. Pinho, A. C. A. Veloso, A. M. Peres, and A. Mendonca. 2006. Casein breakdown in Terrincho ovine cheese: Comparison with bovine cheese and with bovine/ovine cheeses. J. Dairy Sci. 89:2397-2407. https://doi.org/10 .3168/jds.S0022-0302(06)72312-8.

Fox, P. F., P. L. McSweeney, T. M. Cogan, and T. P. Guinee. 2004. Sensory character of cheese and its evaluation. Pages $455-487$ in Cheese - Chemistry, Physics and Microbiology - General Aspects, 3rd ed. Elsevier Academic Press, London, UK.

Hillmann, H., J. Behr, M. A. Ehrmann, R. F. Vogel, and T. Hofmann. 2016. Formation of kokumi-enhancing $\gamma$-glutamyl dipeptides in Parmesan cheese by means of $\gamma$-glutamyltransferase activity and stable isotope double-labeling studies. J. Agric. Food Chem. 64:1784-1793. https://doi.org/10.1021/acs.jafc.6b00113.

Jimenez-Flores, R., Y. C. Kang, and T. Richardson. 1987. Cloning and sequence analysis of bovine beta-casein cDNA. Biochem. Biophys. Res. Commun. 142:617-621. https://doi.org/10.1016/0006 -291X(87)90318-4.

Johnston, S. L., K. E. Kitson, J. W. Tweedie, S. R. Davis, and J. Lee. 2004. $\gamma$-Glutanyl transpeptidase inhibition suppresses milk protein synthesis in isolated mammary cells. J. Dairy Sci. 87:321-329. https://doi.org/10.3168/jds.S0022-0302(04)73171-9.

Kuroda, M., Y. Kato, J. Yamazaki, N. Kageyama, T. Mizukoshi, H. Miyano, and Y. Eto. 2012a. Determination of $\gamma$-glutamyl-valylglycine in raw scallop and processed scallop products using high pressure liquid chromatography-tandem mass spectrometry. Food Chem. 134:1640-1644. https://doi.org/10.1016/j.foodchem.2012 .03 .048 .

Kuroda, M., Y. Kato, J. Yamazaki, Y. Kai, T. Mizukoshi, H. Miyano, and Y. Eto. 2012b. Determination and quantification of $\gamma$-glutamyl-valyl-glycine in commercial fish sauces. J. Agric. Food Chem. 60:7291-7296. https://doi.org/10.1021/jf3012932.

Kuroda, M., Y. Kato, J. Yamazaki, Y. Kai, T. Mizukoshi, H. Miyano, and Y. Eto. 2013. Determination and quantification of the kokumi peptide, $\gamma$-glutamyl-valyl-glycine, in commercial soy sauces. Food Chem. 141:823-828. https://doi.org/10.1016/j.foodchem.2013.03 .070 .

Kuroda, M., and N. Miyamura. 2015. Mechanism of the perception of "kokumi" substances and the sensory characteristics of a kokumi peptide, $\gamma$-Glu-Val-Gly. Flavour (Lond.) 4:11. https://doi.org/10 $.1186 / 2044-7248-4-11$.

Kuroda, M., and N. Miyamura. 2019. Effect of a kokumi peptide, $\gamma$-glutamyl-valyl-glycine, on the sensory characteristics of foods. Pages $85-113$ in Koku in Food Science and Physiology. T. Nishimura and M. Kuroda, ed. Springer Nature Singapore Pte Ltd., Singapore.

Maden, M., V. Altunok, F. M. Birdane, V. Aslan, and M. Nizamlioglu. 2003. Blood and colostrum/milk serum gamma-glutamyltransferase activity as a predictor of passive transfer status in lambs. J. Vet. Med. B Infect. Dis. Vet. Public Health 50:128-131. https:// doi.org/10.1046/j.1439-0450.2003.00629.x.

Maruyama, Y., R. Yasuda, M. Kuroda, and Y. Eto. 2012. Kokum substances, enhancers of basic tastes, induce responses in calciumsensing receptor expressing taste cells. PLoS One 7:e34489. https: //doi.org/10.1371/journal.pone.0034489.

Mercier, J. C., P. Gaye, S. Soulier, D. Hue-Delahaie, and J. L. Vilotte. 1985. Construction and identification of recombinant plasmids carrying cDNAs coding for ovine alpha S1-, alpha S2-, betakappa-casein and beta-lactoglobulin. Nucleotide sequence of alpha S1-casein cDNA. Biochimie 67:959-971. https://doi.org/10.1016/ S0300-9084(85)80291-1.

Miyamura, N., Y. Iida, M. Kuroda, Y. Kato, J. Yamazaki, T. Mizukoshi, and H. Miyano. 2015. Determination and quantification of kokumi peptide, $\gamma$-glutamyl-valyl-glycine in brewed alcohol beverages. J. Biosci. Bioeng. 120:311-314. https://doi.org/10.1016/j .jbiosc.2015.01.018.

Miyamura, N., M. Kuroda, Y. Kato, J. Yamazaki, T. Mizukoshi, and H. Miyano. 2016. Quantitative analysis of $\gamma$-glutamyl-valyl-glycine in fish sauces fermented with koji. Chromatography (Basel) 37:3942. https://doi.org/10.15583/jpchrom.2015.034.

Miyamura, N., M. Kuroda, Y. Kato, J. Yamazaki, T. Mizukoshi, H. Miyano, and Y. Eto. 2014. Determination and quantification of a kokumi peptide, $\gamma$-glutamyl-valyl-glycine, in fermented shrimp paste condiments. Food Sci. Technol. Res. 20:699-703. https://doi .org $/ 10.3136 /$ fstr.20.699.

Ohsu, T., Y. Amino, H. Nagasaki, T. Yamanaka, S. Takeshita, T. Hatanaka, Y. Maruyama, N. Miyamura, and Y. Eto. 2010. Involvement of the calcium-sensing receptor in human taste perception. J. Biol. Chem. 285:1016-1022. https://doi.org/10.1074/jbc.M109 .029165 .

Phewpan, A., P. Phuwaprisirisan, H. Takahashi, C. Ohshima, P. Ngamchuachit, P. Techaruvichit, S. Dirndorfer, C. Dawid, T. Hofmann, 
and S. Keeratipibul. 2019. Investigation of kokumi substances and bacteria in fermented Thai freshwater fish (Pla-ra). J. Agric. Food Chem. acs.jafc.9b06107. https://doi.org/10.1021/acs.jafc.9b06107.

Provot, C., M. A. Persuy, and J. C. Mercier. 1995. Complete sequence of the ovine beta-casein-encoding gene and interspecies comparison. Gene 154:259-263. https://doi.org/10.1016/0378 $-1119(94) 00755-\mathrm{H}$.

Schlieben, S., G. Erhardt, and B. Senft. 1991. Genotyping of bovine kappa-casein (kappa-CNA, kappa-CNB, kappa-CNC, kappa-CNE) following DNA sequence amplification and direct sequencing of kappa-CNE PCR product. Anim. Genet. 22:333-342. https://doi .org/10.1111/j.1365-2052.1991.tb00687.x.

Stewart, A. F., I. M. Willis, and A. G. Mackinlay. 1984. Nucleotide sequences of bovine alpha S1- and kappa-casein cDNAs. Nucleic Acids Res. 12:3895-3907. https://doi.org/10.1093/nar/12.9.3895.

Suzuki, H., and C. Yamada. 2007. Improvement of the flavor of amino acids and peptides using bacterial $\gamma$-glutamyltranspeptidase. Pages 227-232 in Recent Highlight in Flavor Chemistry \& Biology. T. Hofmann, W. Meyerhof, and P. Schieberle, ed. Deutsche Forschungsanstalt fur Lebensmittelchemie; Munchen, Germany.

Toelstede, S., A. Dunkel, and T. Hofmann. 2009. A series of kokumi peptides impart the long-lasting mouthfulness of matured Gouda cheese. J. Agric. Food Chem. 57:1440-1448. https://doi.org/10 $.1021 /$ if803376d.

Toelstede, S., and T. Hofmann. 2009. Kokumi-active glutamyl peptides in cheeses and their biogeneration by Penicillium roquefortii. J. Agric. Food Chem. 57:3738-3748. https://doi.org/10.1021/ jf900280j.

Ueda, Y., M. Yonemitsu, T. Tsubuku, M. Sakaguchi, and R. Miyajima. 1997. Flavor characteristics of glutathione in raw and cooked foodstuffs. Biosci. Biotechnol. Biochem. 61:1977-1980. https://doi .org/10.1271/bbb.61.1977.

Ueda, Y., M. Sakaguchi, R. Hirayama, R. Miyajima, and A. Kimizuka. 1990. Characteristic flavor constituents in water extract of garlic. Agric. Biol. Chem. 54:163-169.

Zhao, C. J., and M. G. Ganzle. 2016. Synthesis of taste-active $\gamma$-glutamyl dipeptides during sourdough fermentation by Lactobacillus reuteri. J. Agric. Food Chem. 64:7561-7568. https://doi.org/ 10.1021/acs.jafc.6b02298.

\section{ORCIDS}

Motonaka Kuroda @ https://orcid.org/0000-0002-7575-6481 